\title{
Retraction Note to: Prediction of PM2.5 concentration in ambient air and safety of sports training based on Android dynamic monitoring
}

\author{
Yuliang Zhang ${ }^{1} \cdot$ Tingting Wang $^{1}$
}

Published online: 4 November 2021

C) Saudi Society for Geosciences 2021

Retraction Note to: Arabian Journal of Geosciences (2021) 14: 1845 https://doi.org/10.1007/s12517-021-08185-x

The Editor-in-Chief and the Publisher have retracted this article because the content of this article is nonsensical. The peer review process was not carried out in accordance with the Publisher's peer review policy. The authors have not responded to correspondence regarding this retraction.

The original article can be found online at https://doi.org/10.1007/ s12517-021-08185-x

Tingting Wang

zhangy150325@163.com

1 Guangdong Ocean University Cunjin College, Zhanjiang 524000, Guangdong, China 